\title{
Two staged surgical treatment of a low rectal tumor presented with Fournier's gangrene: A case report
}

\author{
Osman Zekai Öner, Barış Rafet Karakaş, Rojbin Karakoyun Demirci, \\ Nuray Ayper Öngen, Mani Habibi, Nurullah Bülbüller
}

\begin{abstract}
Introduction: Rectal cancer presenting with Fournier's gangrene (FG) is a very rare lifethreatening surgical emergency that presents a challenge for clinicians for diagnosis and management. Case Report: We report case of a 57-year-old male patient having a low rectal tumor and presenting with Fournier's gangrene. The patient first underwent surgical debridement and fecal diversion for treatment of Fournier's gangrene. Following a fast and successful wound healing with the application of a vacuum assisted wound closure device, surgical removal of the rectal tumor was performed on the 11th day. After receiving chemotherapy and radiotherapy and one year of follow-up, the patient is currently disease free. Conclusion: In our opinion a fecal diversion is necessary in case of Fournier's gangrene not only to control the source of infection but in cases of Fournier's gangrene also to provide a chance of applying a vacuum assisted wound closure device which dramatically shortens the duration of wound contraction and granulation in Fournier's gangrene. After this initial effort is
\end{abstract}

Osman Zekai Öner ${ }^{1}$, Barış Rafet Karakaş ${ }^{1}$, Rojbin Karakoyun Demirci ${ }^{1}$, Nuray Ayper Öngen ${ }^{1}$, Mani Habibi ${ }^{1}$, Nurullah Bülbüller ${ }^{2}$

Affiliations: ${ }^{1} \mathrm{MD}$, Department of Surgery, Antalya Training and Research Hospital, Antalya, Turkey; ${ }^{2}$ Associate Prof, MD, Department of Surgery, Antalya Training and Research Hospital, Antalya, Turkey.

Corresponding Author: Osman Zekai Öner, MD, Department of General Surgery, Antalya Training and Research Hospital, Antalya-07030, Turkey GSM: +90 (532) 7661078 ; Phone: +90 (242) 24944 00-3999; Fax: +90 (242) 24944 62; E-mail: osmanzekai@yahoo.com

Received: 15 September 2012

Accepted: 21 November 2012

Published: 01 May 2013 accomplished a definitive surgery can be successfully implemented.

Keywords: Rectum adenocarcinoma, Fournier's gangrene, Necrotizing fasciitis, Staged surgical treatment

$* * * * * * * * *$

Öner OZ, Karakaș BR, Demirci RK, Öngen NA, Habibi M, Bülbüller N. Two staged surgical treatment of a low rectal tumor presented with Fournier's gangrene: A case report. International Journal of Case Reports and Images 2013;4(5):270-274.

$$
* * * * * * * * *
$$

doi:10.5348/ijcri-2013-05-310-CR-7

\section{INTRODUCTION}

Rectal cancer is the third most common cancer in the Western world. It usually presents with pain, rectal bleeding, tenesmus or alteration in bowel habits [1]. However, rectal cancer may not always present with such classical symptoms. Presence of tumor perforation below the peritoneal reflection might cause a clinical picture resembling Fournier's gangrene (FG). [2, 3]

Fournier's gangrene is a necrotizing fasciitis of the perineal, perianal or genital areas and associated with high morbidity and mortality. Although the presentation of rectal cancer in the form of Fournier's gangrene is a rare phenomenon, this life-threatening condition requires urgent, radical surgical debridement and administration of broad spectrum antibiotics $[4,5]$. In the majority of previously reported colorectal tumor cases presenting with FG, the first goal of the therapy was achieving infection control with surgical debridement and eventually fecal diversion. However, despite appropriate treatment only few patients have 
survived and undergone chemo or radiotherapy without tumor resection [6-9].

Through this case report, we highlight the importance of recognizing and managing of FG early in the setting of low rectal cancer. We present a two-stage surgical strategy for the treatment of FG and its successful outcome after one year clinical follow-up.

\section{CASE REPORT}

A 57-year-old male patient was referred to our hospital for severe scrotal swelling and pain. Patient had no history of a systemic disease, substance abuse or any other condition that could alter his immune status. Physical examination on admission revealed high fever $\left(38,7^{\circ} \mathrm{C}\right)$, hypotension $(80 / 60 \mathrm{mmHg})$ and tachycardia (130/min). The skin of the scrotum and perineum was swollen. The patient had an edema that had spread in the inguinal regions bilaterally and extended up word and laterally along the inner surface of the left thigh. A foul-smelling purulent discharge from the necrotic skin in the scrotum was also present (Figure 1). Digital rectal examination revealed an irregular mass filling the left side of the lower rectum that was three $\mathrm{cm}$ in length and extending to the dentate line distally. Additionally, patient had grade IV internal hemorrhoids with thrombosis. The laboratory tests showed high white blood cell count $\left(22 \times 10^{3} / \mathrm{mm}^{3}\right)$, low hemoglobin $(7.8$ $\mathrm{g} / \mathrm{dL})$ and low albumin $(1.8 \mathrm{~g} / \mathrm{dL})$.

Following the diagnosis of FG, broad spectrum antibiotics for empiric treatment were commenced and the patient underwent emergency surgery. All necrotic tissue was removed quickly and aggressively (Figure 2). Both testes were preserved and left in place. The removal of the tumor was deferred to a later date. Because of the patient's septic shock and poor general condition. A laparotomy was performed for fecal diversion by a low midline incision. Following a fast abdominal exploration which revealed no abnormal finding above the peritoneal reflection, sigmoid colon was diverted by a linear stapler (Autosuture Endo GIA, Covidien, Mansfield, MA, USA) and an end sigmoid colostomy was performed to ensure the infections source control.

The patient was followed in the intensive care unit for the first two postoperative days. Extubation was done the next morning of surgery and oral nutrition was allowed in the evening of first day. On the first postoperative day in intravenous infusion $50 \mathrm{~mL}, 20 \%$ human albumin every $12 \mathrm{~h}$ was started and continued for three days. A referred was sent to infection diseases clinic on postoperative day-2 and the previously given empiric antibiotics (imipenem-cilastatin sodium 500 $\mathrm{mg}$ intravenously every $6 \mathrm{~h}$, metronidazole $500 \mathrm{mg}$ intravenously every $8 \mathrm{~h}$ and clindamycin $900 \mathrm{mg}$ every $8 \mathrm{~h}$ ) were continued for 10 days according to their recommendations.

In addition to bedside minor debridement, vacuum assisted wound closure device was applied on the postoperative day-2 with local anesthesia (Figure 3).
The polyurethane sponge of this device was changed every other day and the wound was regularly inspected. After four applications of this sponge, on postoperative day-10, the defect on the pelvic floor was completely covered with a clean granulation tissue (Figure 4).

Meanwhile the patient underwent total colonoscopy, abdominal computed tomography scan and pelvic magnetic resonance imaging. Biopsies obtained at colonoscopy confirmed the diagnosis of rectal adenocarcinoma. Tomography and magnetic resonance imaging revealed no findings which would contraindicate the resection. Patient's general condition was fine and he could undergo the Miles procedure on postoperative day-11. The space between sacrum and posterior wall of the rectum where mesorectum should exist was hardened with fibrotic tissue but the dissection was carried out as in total mesorectal excision. The defect on perineum and both testes was closed by the skin flaps derived from the medial surfaces of both thighs following the abdominoperineal resection (Figure 5). Patient's postoperative course was uneventful. The

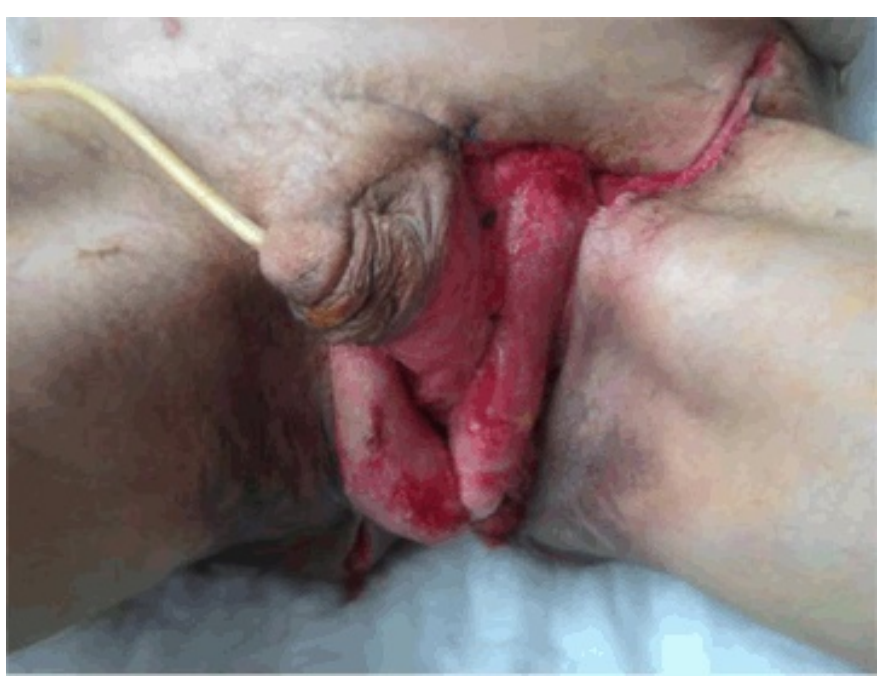

Figure 1: Preoperative condition of the perineum.

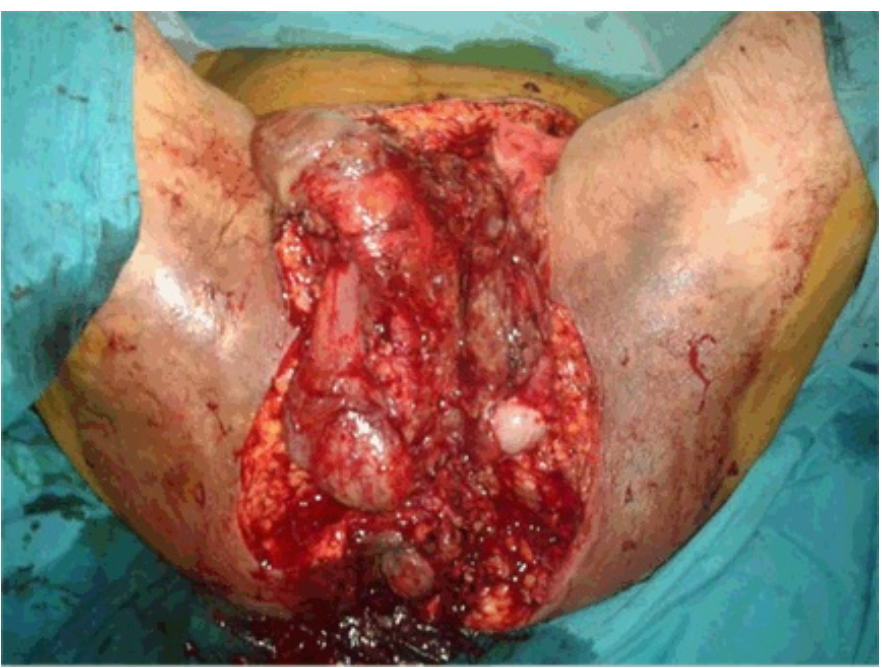

Figure 2: The condition of the perineum following aggressive debridement. 


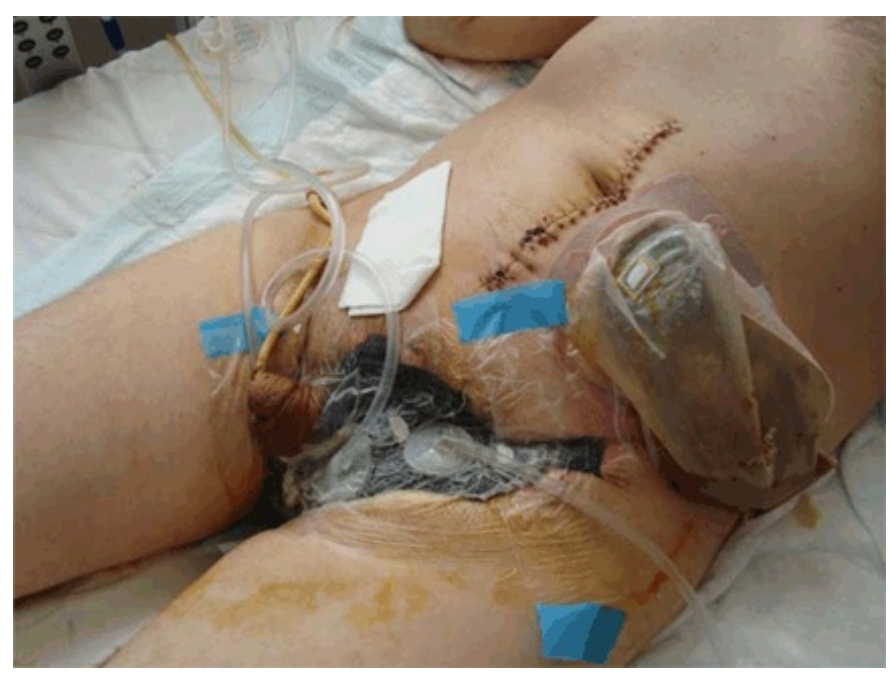

Figure 3: Postoperative day-3 showing with vacuum assisted wound dressing.

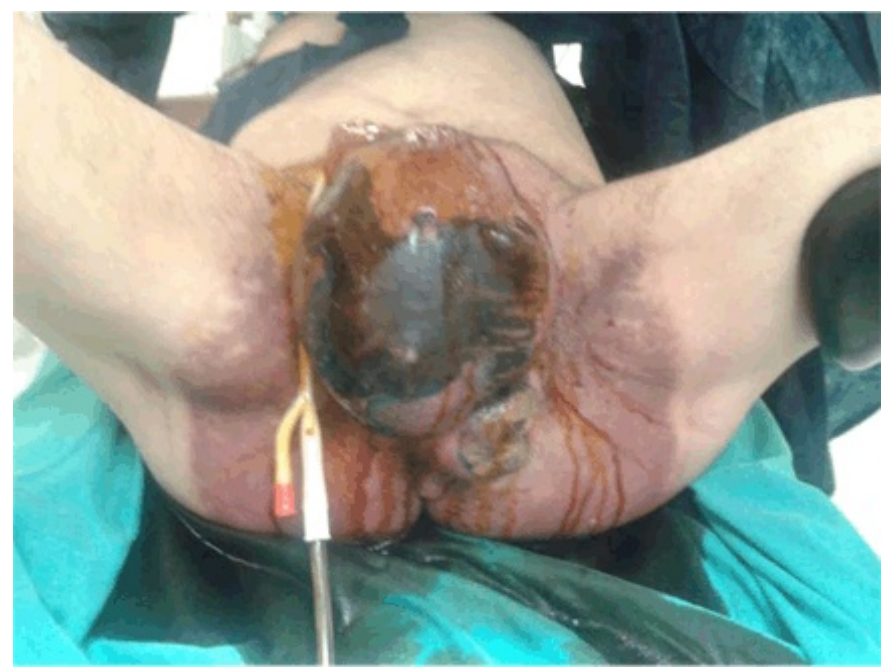

Figure 4: Postoperative day-10 showing the contracted wound and granulation tissue.

pelvic suction drains were removed on postoperative day- 3 and the patient was discharged on postoperative day-14.

In the histopathological report, the tumor was found to be stage $\mathrm{T}_{3} \mathrm{NX}$, moderately differentiated adenocarcinoma with negative surgical margins. Despite through gross examination no lymph nodes could be identified in the resected specimen histologically. The patient was referred to medical and radiation oncology clinics where he received six cycles of adjuvant chemotherapy with fluorouracil and folinic acid. During the second cycle of chemotherapy, pelvic radiotherapy was also given as adjuvant. After one year of follow-up, the patient is currently disease free as evidenced by computed abdominal tomography and total colonoscopy.

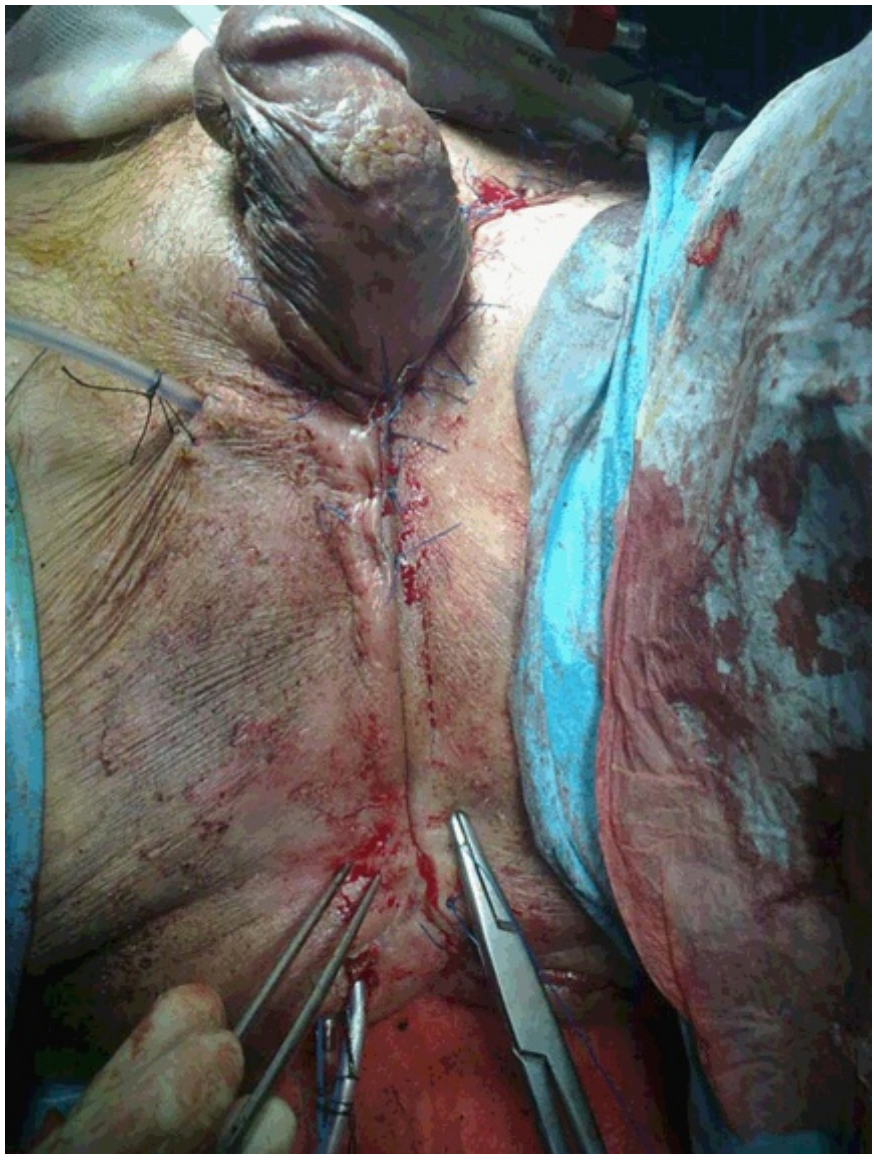

Figure 5: The condition of the perineum following abdominoperineal resection.

\section{DISCUSSION}

In majority of the previously reported colorectal tumor cases presenting with FG, only few patients have survived the infection and undergone further chemo or radiotherapy without any tumor resection. Of these, in only one exceptional paper reported by Carr et al. in 2010, a case presenting with a very similar clinical picture to our patient plus having a diagnose of rectal carcinoma underwent aggressive debridement and abdominoperineal resection simultaneously [10]. The patient survived, but Carr et al. underlined that the surgical decision of abdominoperineal resection was challenging in the presence of such a serious infection.

We did not choose to go through an abdominoperineal resection at first operation as the patient was showing signs and symptoms of severe septic shock. Moreover, we did not have a confirmed diagnosis of rectal malignancy to justify such a radical surgery.

It was unusual that pathologists could not identify any lymph node in the gross specimen. But at the first debridement the soft tissue surrounding the rectum was removed circumferentially and there were barely any soft tissue left till the proximal section of the sacrum 
near promontorium. We think that this could be a reason for not finding any lymph nodes in gross specimens.

Although there are controversies for fecal diversion in the treatment of $\mathrm{FG}$, if a preventive colostomy is planned, it should be performed during the initial debridement [11]. In our opinion, a fecal diversion was necessary not only to control the source of the infection but also for the ease of implementing a vacuum assisted wound closure device which accelerated the formation of a healthy granulation tissue safely [12].

\section{CONCLUSION}

In this case report the successful outcome of a two staged surgical approach for the treatment of a rectal tumor with Fournier's gangrene is presented. We think that a fecal diversion is necessary to control the source of infection and to provide a chance of applying a vacuum assisted wound closure device which dramatically shortens the duration of wound contraction and granulation. After this initial surgery, a through and definitive surgery can be successfully performed.

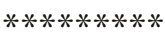

\section{Author Contributions}

Osman Zekai Öner - Conception and design, Acquisition of data, Analysis and interpretation of data, Drafting the article, Critical revision of the article, Final approval of the version to be published

Barış Rafet Karakaş- Analysis and interpretation of data, Drafting the article, Critical revision of the article, Final approval of the version to be published

Rojbin Karakoyun Demirci- Drafting the article, Final approval of the version to be published

Nuray Ayper Öngen- Drafting the article, Final approval of the version to be published

Mani Habibi- Acquisition of data, Drafting the article, Final approval of the version to be published

Nurullah Bülbüller- Drafting the article, Critical revision of the article, Final approval of the version to be published

\section{Guarantor}

The corresponding author is the guarantor of submission.

\section{Conflict of Interest}

Authors declare no conflict of interest.

\section{Copyright}

(C) Osman Zekai Öner et al. 2013; This article is distributed under the terms of Creative Commons Attribution 3.0 License which permits unrestricted use, distribution and reproduction in any means provided the original authors and original publisher are properly credited. (Please see www.ijcasereportsandimages.com /copyright-policy.php for more information.)

\section{REFERENCES}

1. Available at: http://globocan.iarc.fr/pie_pop.asp? selection $=221900 \&$ title $=$ World \&sex $=0 \&$ type $=0 \& w i$ ndow=1\&join=1\&submit=\%AoExecute\%A Accessed 2012 September 10.

2. Gamagami RA, Mostafavi M, Gamagami A, Lazorthes F. Fournier's gangrene: an unusual presentation for rectal carcinoma. Am J Gastroenterol 1998;93(4):657-8.

3. Gould SW, Banwell P, Glazer G. Perforated colonic carcinoma presenting as epididymo-orchitis and Fournier's gangrene. Eur J Surg Oncol 1997;23(4):367-8.

4. Clayton MD, Fowler JE Jr, Sharifi R, Pearl RK. Causes, presentation and survival of fifty-seven patients with necrotising fasciitis of the male genitalia. Surg Cynecol Obstet 1990;170(1):49-55.

5. Basoglu M, Ozbey I, Atamanalp SS, et al. Management of Fournier's gangrene: review of 45 cases. Surg Today 2007;37(7):558-63.

6. Gupta PJ. Rectal cancer presenting as ischio-rectal abscess and Fournier's gangrene--a case report. Eur Rev Med Pharmacol Sci 2010;14(2):139-40.

7. Dewire DM, Bergstein JM. Carcinoma of the sigmoid colon: an unusual cause of Fournier's gangrene. J Urol 1992;147(3):711-2.

8. Ruiz-Tovar J, Córdoba L, Devesa JM. Fournier gangrene: first manifestation of occult rectal cancer. Acta Chir Belg 2011;111(5):329-31.

9. Onita M, Hornung E, Ciobanu C, Olariu T, Onita C. [Fournier's gangrene--atypical onset for lower rectal cancer]. Chirurgia (Bucur) 2005;100(4):395-9.

10. Carr JA. Perforated rectal cancer presenting as Fournier's gangrene. J Clin Oncol 2010;28(30):e605-6.

11. Akcan A, Sözüer E, Akyildiz H, Yilmaz N, Küçük C, Ok E. Necessity of preventive colostomy for Fournier's gangrene of the anorectal region. Ulus Travma Acil Cerrahi Derg 2009;15(4):342-6.

12. Ozturk E, Ozguc H, Yilmazlar T. The use of vacuum assisted closure therapy in the management of Fournier's gangrene. Am J Surg 2009;197(5):660-5. 
Access full text article on other devices

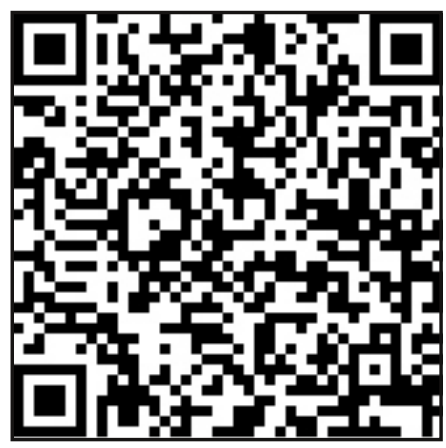

Access PDF of article on other devices

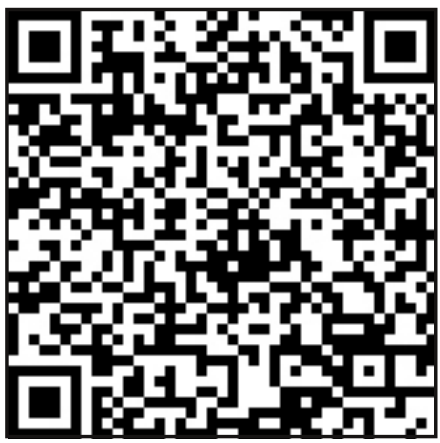

